\title{
An Unusual Bronchoscopic Finding
}

\author{
Ninotchka L. Sigua ${ }^{a}$ Shawn D. Teague ${ }^{b}$ Praveen N. Mathur ${ }^{a}$ \\ a Division of Pulmonary, Allergy, Critical Care and Occupational Medicine and ${ }^{\mathrm{b}}$ Department of Radiology, \\ Indiana University, Indianapolis, Ind., USA
}

A 55-year old female was seen in clinic for 6 weeks of nonproductive cough. Significant medical history included recurrent esophageal adenocarcinoma despite esophagectomy, chemotherapy and radiotherapy. Chest CT revealed recurrent esophageal tumor at the gastric pull-through site. Flexible bronchoscopy was performed to evaluate for possible tracheoesophageal fistula, however, none was found. Interestingly, an incidental finding of a five-orifice left upper lobe (LUL) bronchus was seen (fig. 1). Bronchoscopic exploration of the five LUL segments revealed patent bronchi without atresia. Further anatomic evaluation with CT scan showed the anterior, apico-posterior and posterior segments, and two lingular subsegments arising directly from the LUL bronchus (fig. 2). The patient had no other congenital anomalies. Cough resolved with treatment of gastroesophageal reflux disease.

Tracheobronchial anatomic variations arise from embryogenic anomalies of supernumerary lung buds or lung buds arising from atypical sites. Congenital lobar and segmental bronchial variations are more common than tracheal or main bronchial anomalies, and they are
Fig. 1. Fiberoptic bronchoscopy revealed a five-orifice LUL. A = Anterior; $A P=$ apico-posterior; $\mathrm{P}=$ posterior; $\mathrm{L}=$ lingula. Fig. 2. Sagittal CT image of the chest showing five-orifice LUL bronchus. A = Anterior; $\mathrm{AP}=$ apico-posterior; $\mathrm{P}=$ posterior; $\mathrm{L}=$ lingula.

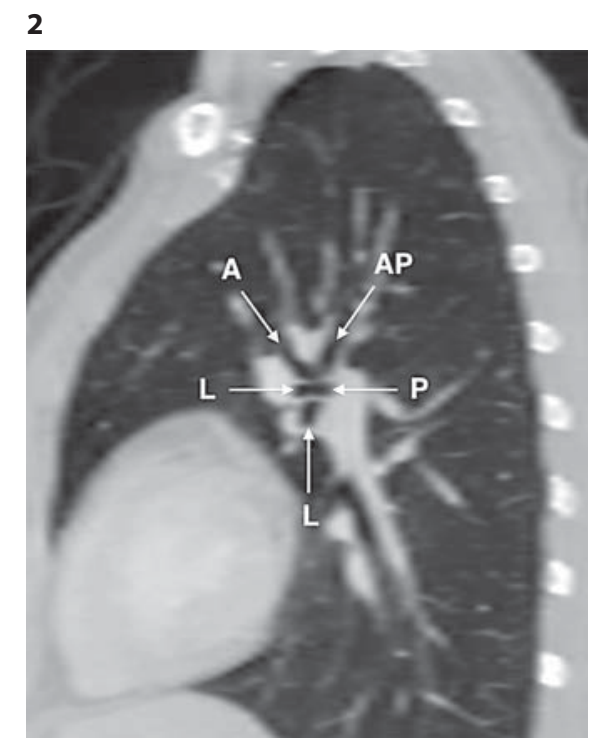

\section{KARGER}

Fax +4161306 1234 E-Mail karger@karger.ch www.karger.com (c) 2009 S. Karger AG, Basel

0025-7931/10/0803-0254\$26.00/0

Accessible online at:

www.karger.com/res

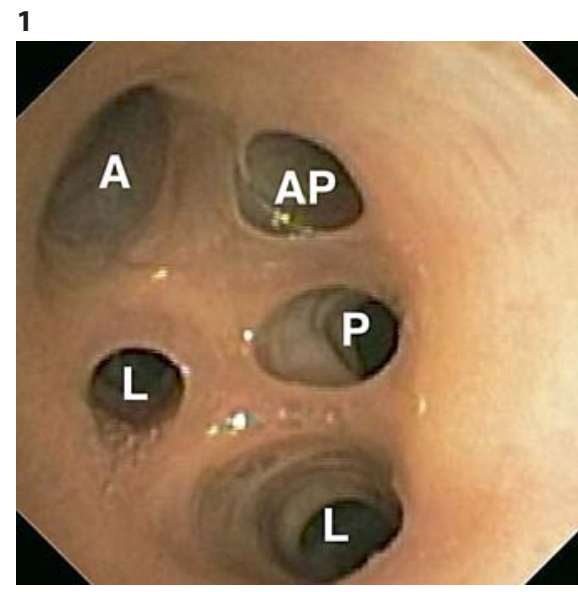

Praveen N. Mathur, MBBS

550 University Boulevard, Suite 4903

Indianapolis, IN 46202 (USA)

Tel. +1 317278 2894, Fax +1 317274 2136, E-Mail pmathur@iupui.edu 
more common in the upper lobe, especially on the right side. In the LUL, the principal variation is an accessory anterior bronchus with associated downward displacement of an anterior segmental bronchus [1]. In 2000, Doshi and Mehta [2] first reported a trifurcate left main bronchus, which gave rise to the upper lobe, lingular and left lower lobe bronchi. To our knowledge, there has been no report of a five-orifice LUL bronchus in the literature.

The incidence of bronchial abnormalities seen during bronchoscopy or thoracotomy is estimated at $0.7-1.4 \%$, with most cases being asymptomatic [1]. Knowledge of normal bronchial anatomy and its variations is imperative during bronchoscopy or any thoracic surgery as this helps precisely delineate the anatomic structures of the lung, resulting in greater operative success with lower morbidity.

References

1 Gonlugur U, Efeoglu T, Kaptanoglu M, Akkurt I: Major anatomical variations of the tracheobronchial tree: bronchoscopic observation. Anat Sci Int 2005;80:111-115.

$\checkmark 2$ Doshi A, Mehta AC: Trifurcation of the left main bronchus. J Bronchol 2000;7:324-325. 